\title{
Micropatterned Coatings for Guided Tissue Regeneration in Dental Implantology
}

\author{
A. Pelaez-Vargas, D. Gallego-Perez, N. Higuita-Castro, A. Carvalho, L. Grenho, \\ J.A. Arismendi, M.H. Fernandes, M.P. Ferraz, D.J. Hansford and F.J. Monteiro
}

Additional information is available at the end of the chapter

http://dx.doi.org/10.5772/50838

\section{Introduction}

Dento-alveolar trauma and congenital absences are the most important causes of edentulism that are not associated with bacteria. However, the World Health Organization reports show that dental caries and periodontitis, two conditions of bacterial origin, are the most frequent oral diseases in humans [1]. These conditions might be avoided if an adequate oral preventive health policy is implemented, including preventive and educational measures that, regardless of the population's socioeconomic factors, have shown their effectiveness. Despite these facts, tooth extraction ${ }^{1}$, defined as the surgical removal of a tooth, is currently the most frequent surgical procedure in the world [1].

Tooth loss or edentulism affects the aesthetics and function of the stomatognathic system. The missing interproximal contact produces an intra-arch imbalance that is visible as dental misalignment and the formation of anterior/posterior diastema. Additionally, the tooth distal to the extraction site will drift mesially into the space, thus creating an oclusal collapse. Inter-arch disharmonies are observed as occlusal collapse, supereruption of antagonist teeth, and alteration of the vertical dimension of occlusion. The synergy of inter-/ intra- arch disequilibrium is associated with ATM dysfunction, muscle hyperactivity, nutritional imbalances, tooth wear, mobility, and potential harmful contact areas during mandibular eccentric movements or otologic symptoms [2].

Recovering aesthetics and function is only possible using some oral rehabilitation procedures such as fixed or removable prostheses. In the fixed restorations, titanium implant-based therapy appears as the "gold standard", considering that successful rates of $\sim 95 \%$ after 5 years have been reported.

${ }^{1}$ Tooth extraction was indexed (1965) in the MESH of the National Library of Medicine (NLM). Some synonyms are dental extraction, exodontia or pulling teeth. 
The history of implantology has been divided in two different phases, namely the preosseointegration and post-osseointegration eras. Many audacious designs were developed to be used in sub- or endosteal areas in the former. The most commonly used implants were blades and plaques based on metallic alloys such as cobalt-chromium-molybdenum and stainless steel (Figure 1). These types of devices have been associated to doubtful long-term clinical success. Initial clinical research reported by Branemark was criticized, but the basis for a new philosophy in dental therapy had been initiated. After completing training in Sweden, Zarb and colleagues from Toronto started a longitudinal study to verify the
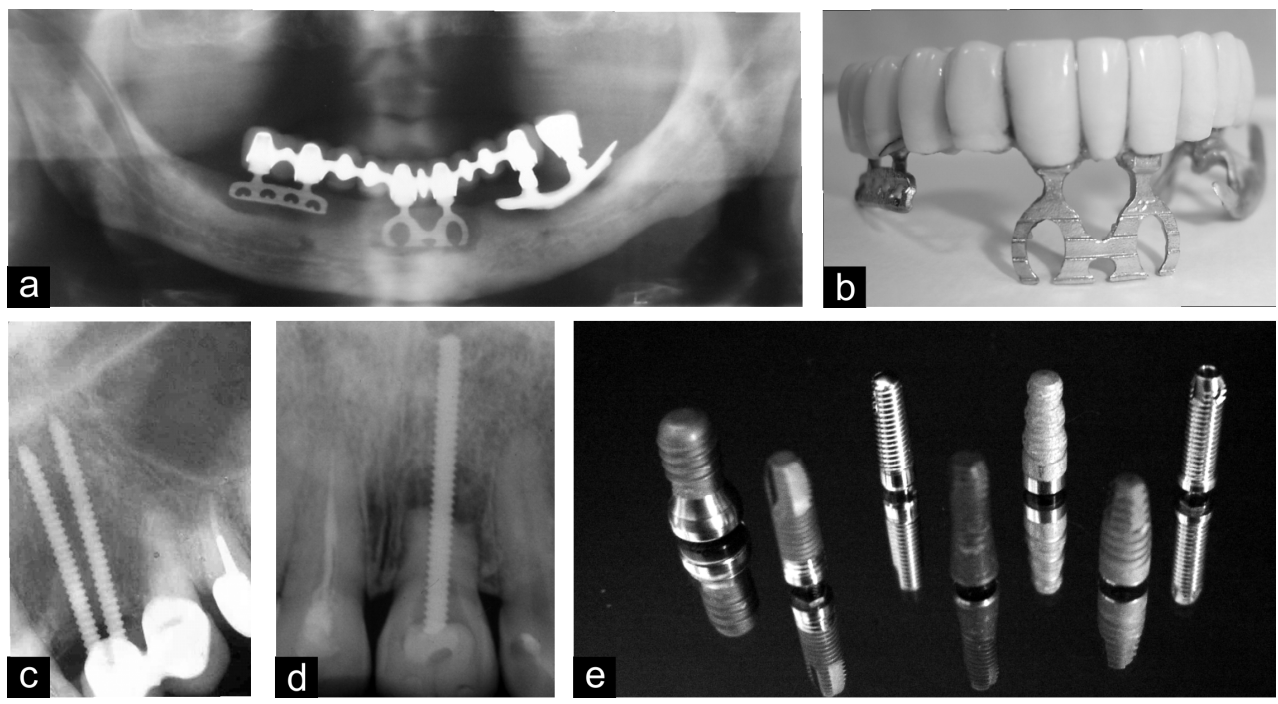

Figure 1. History of dental implants. (a,b) Panoramic radiography and general view of a failed total rehabilitation supported on blade/plate-shaped implants. (c) Parallel pins implant, (d) Endosteal endodontic stabilizers and (e) different designs and surfaces of screw dental implants.
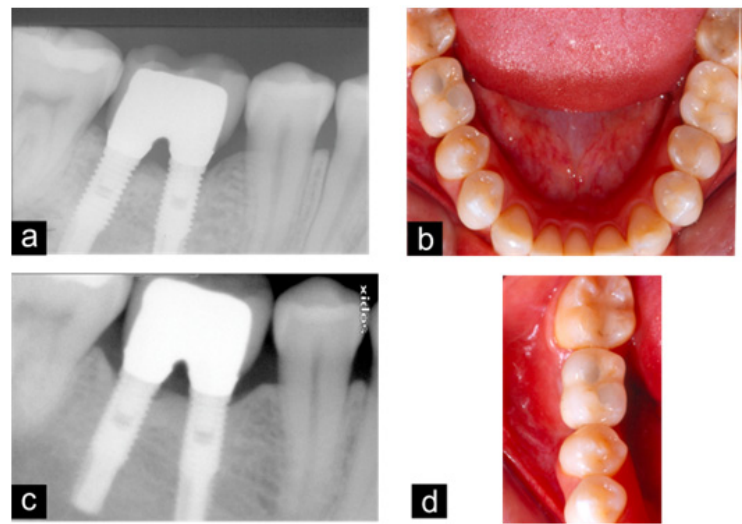

Figure 2. Double implants to replace a mandibular molar. (a,b) Periapical radiography and occlusal view of the final rehabilitation. (c,d) Periapical radiography and detailed occlusal view after 10 years of function. 

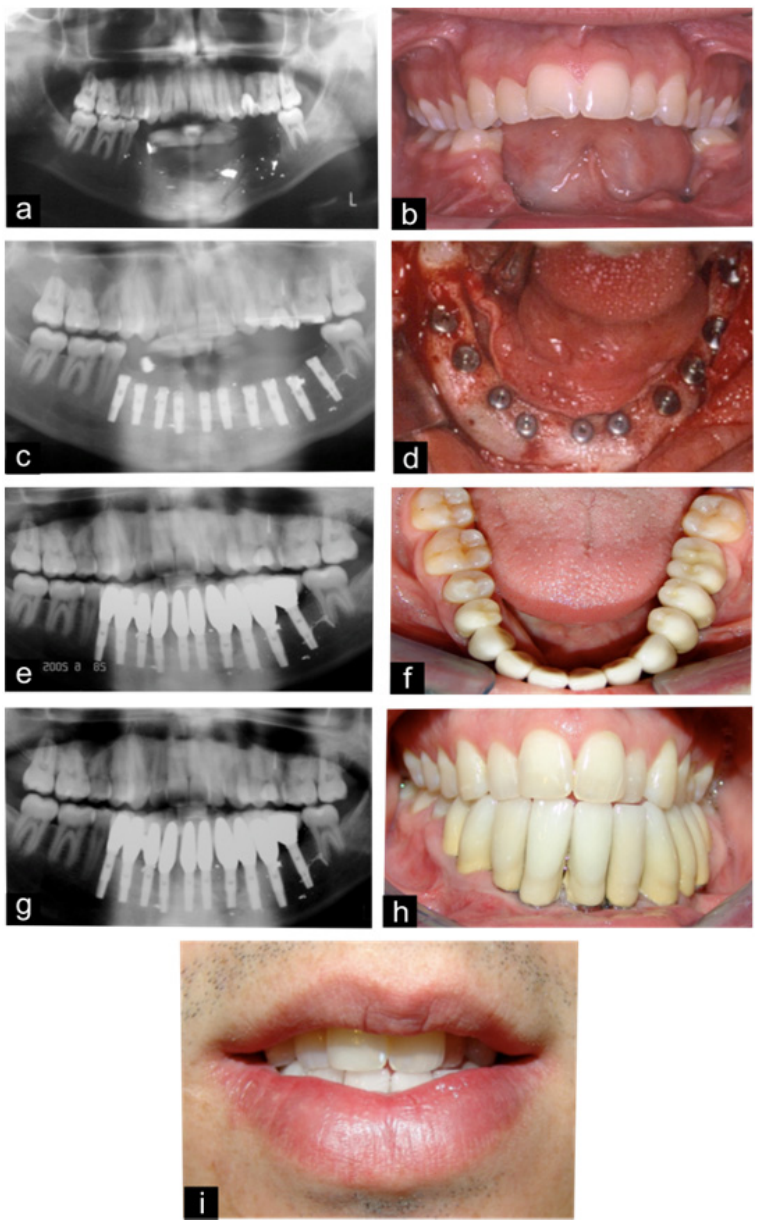

Figure 3. Ten-year follow-up of a successful implant-based rehabilitation after trauma. (a) Initial panoramic radiography, where radiopaque zones compatible with metallic residues are observed. (b) Initial clinical view. Note the extensive loss of mandibular teeth and their alveolar process. (c, d) Surgical phase: ten implants were placed in two surgical treatment phases after a procedure of distraction-based osteogenesis for vertical bone augmentation. (e,f) Final restorations exhibited an increased length to obtain a compensation of the vertically lost bone dimension. (g,h) Panoramic radiography and intraoral view after ten years of function. Note that the restoration is maintained in a good aesthetic condition. (i) Clinical view in labial resting position.

possibilities of osseointegrated implants [3]. In 1982, the concept of osseointegration was discussed in a meeting in Toronto attended by people from the most important dental schools in North America. For more detailed information about the first steps of osseointegrated implants, the reader is referred to more specific literature $[3,4]$. Branemark's work described osseointegration as a biological phenomenon involving direct contact between bone and Ti surfaces, allowing for a new philosophy of therapy. 
In general, it is accepted that implant therapy is a predictable treatment without any contraindications for partially and fully edentulous patients. However, several factors, such as implant design, surgical procedure, anatomic and osseous conditions, systemic diseases, prosthetic design (Figure 2), and two-stage or immediate loading may affect the prognosis and long-term success (Figure 3). A poor prognosis was observed in patients with insufficient quality and/or quantity of bone receptor. Patients exhibiting poor quality of bone (type IV) in the posterior area of the maxilla had a 35\% implant failure. This retrospective study indicated that patients with type I, II and III showed only $3 \%$ failure [5].

Systemic diseases are potential factors that affect the prognosis. The available information is derived from empirical observational studies where multifactorial risks are considered. Moy et al. showed a 10-year retrospective cohort study where 1140 patients were evaluated. Their results presented evidence that smoking, history of diabetes, head and neck radiation and postmenopausal estrogen therapy were correlated with a significantly increased failure rate, while gender, hypertension, coronary arterial disease, pulmonary disease, steroid therapy, chemotherapy and absence of hormone replacement therapy for post-menopausal women were not associated with increased risk in implant failure [6]. This study concluded that there are no absolute medical contraindications to dental implant rehabilitation, although they must be individually considered for each new patient.

The decision to put implants in patients treated for aggressive periodontitis is a challenge since controlled studies with large sample sizes are not available. Some case reports showed approximately $8 \%$ failure in patients previously treated for aggressive periodontitis. However, all the evaluated implants were placed in patients that had been previously treated for several years before the implants were put in place [7]. Until more evidence becomes available, factors such as time before therapy, the presence of natural treated teeth or immune compromise might render these clinical situations unpredictable.

Reduced alveolar bone height appears as an important consideration when evaluating the prognosis of dental implants. Two different approaches are used to achieve clinical success. In situations of an extremely reduced amount of bone, the surgeon may employ bone augmentation procedures (Figure 3 and 4), which result in higher costs, greater morbidity, and longer treatment times. Another possibility includes the use of short implants, which are defined as devices shorter than 6 to $10 \mathrm{~mm}$ [8]. Conflicting information is available about the success of this type of implants, with some authors reporting that short implants are unpredictable in cases of poor bone quality. However, alternative treatments are viable if other favourable factors are considered. A survival rate of approximately $94 \%$ for a fiveyear observation period was observed [8-10]. However, short implants have mechanical disadvantages as a consequence of implant-crown ratios and the amount of osseointegrated area around the implant [11].

In the last decade, there has been an important discussion related to loading implants immediately. Branemark's group postulated that early loading affects the prognosis due to a fibrous capsule that may develop due to micro-movements, thus affecting osseointegration [12]. They introduced the two-phase surgical procedure, in which the implant is submerged 
under gingival tissue and maintained unloaded during a 3 to 6-month period. However, new approaches have been introduced that include immediate loading based on the primary stability during surgical procedure and surface bioactivity [13].

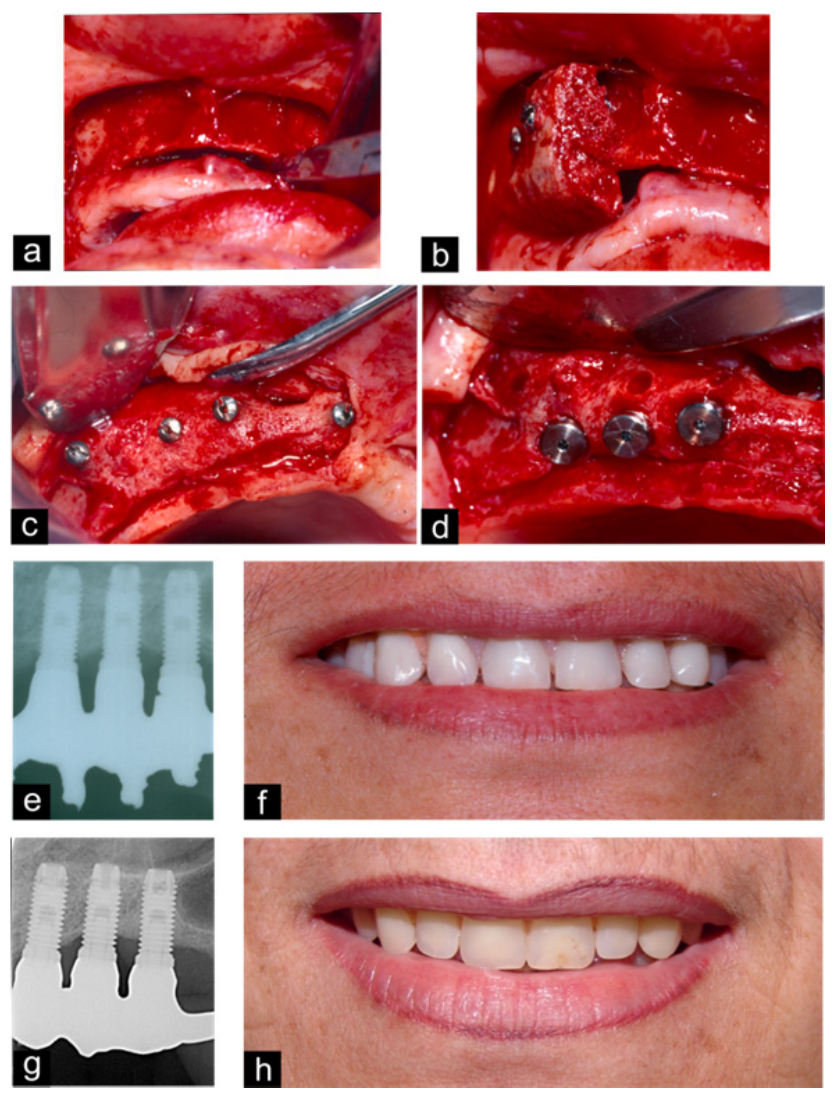

Figure 4. Fourteen-year follow-up of a successful implant-based rehabilitation. (a) Full-thickness flap reflection reveals the extension of missing bone in the buccal aspect of the maxilla. (b) The use of monocortical block graft to reconstruct the horizontal deficiency of the maxilla. (c) After 6 months tissue exhibits good healing. (d) Three implants were placed in this site and submerged for a six-month period. $(\mathrm{e}, \mathrm{f})$ Periapical radiography and clinical photography of complete restoration after treatment and $(\mathrm{g}, \mathrm{h})$ Periapical radiography and clinical view after 14 years of function.

The long-term success of an implant largely depends on the equilibrium between osseointegration and epithelial/connective tissue attachment. A complete soft tissue seal protects the newly formed bone from bacterial products originated in the oral environment.

Several animal and in vitro studies showed similar epithelial and connective structures between the gingiva and the peri-implant mucosa. The outer surface of the peri-implant mucosa is lined by a stratified keratinized oral epithelium that is continuous, with a junctional epithelium attached to the Ti surface by a basal lamina and hemidesmosomes. 
The non-keratinized junctional epithelium is only a few cell layers thick in the apical portion and is separated from the alveolar bone by collagen-rich connective tissue. This 3 to $4 \mathrm{~mm}$ biological barrier, formed irrespective of the original mucosal thickness, protects the osseointegration zone from factors released by the plaque and the oral cavity [14]. The main differences between the soft tissues around natural teeth and those around implants are the collagen fibres orientation, which run parallel from the implant surface to the crest bone, the low number of fibroblasts, and the reduced vascularization of the scar tissue.

An osseointegrated implant is a good alternative to replace missing teeth, but they are not exempt from failure and complications (Figure 5). Oral implant failures have been classified as: 1) biological failures, which can be observed before loading and are associated with reduced osseointegration. If they take place after loading, they are associated with failing to maintain the achieved osseointegration; 2) mechanical failures, which can be observed as implant or prosthetic structural failures; 3) iatrogenic failures, mainly associated with procedures that affect anatomical structures or the misalignment of implants, which render them impossible to restore; and 4) failures by inadequate patient adaptation that include phonetical, aesthetical or psychological problems [15].
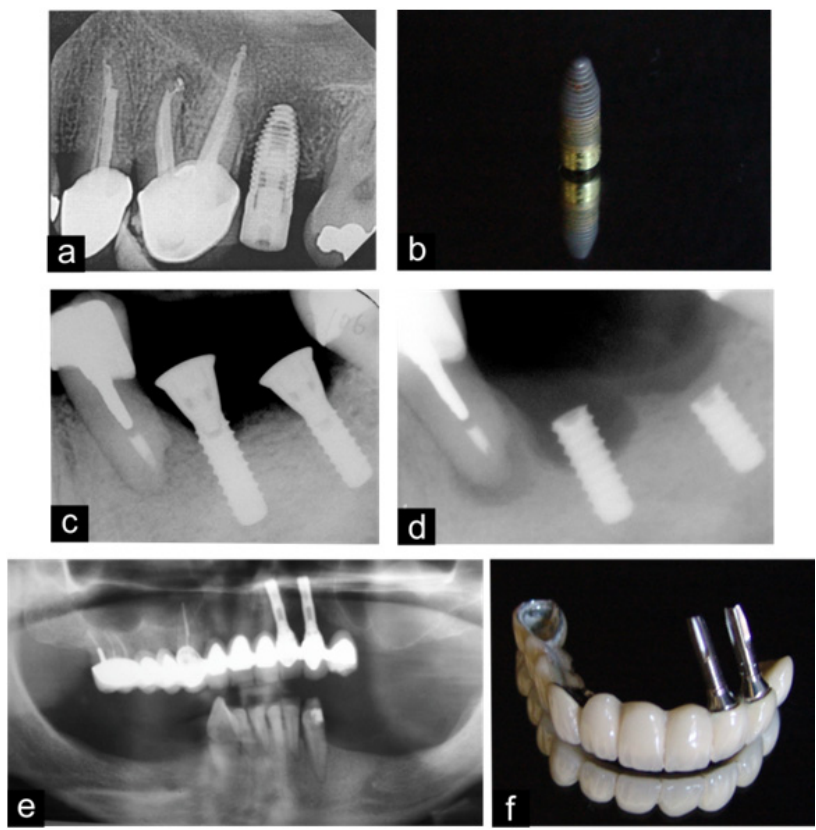

Figure 5. Different failure types in dental implantology. (a,b) Periapical radiography shows a radiolucent lesion on the mesial surface associated with bone resorption and sign of mobility. Photography shows the implant after removal. (c,d) Periapical radiographies show two posterior fractured implants. Fracture was apparently caused by bruxism. Note in the radiography (d) that the more anterior implant exhibits a large radiolucent zone as bone losses and the adjacent tooth shows an apical lesion. (e,f) Failure of full restoration on implants and natural teeth was caused presumably by poor design and support. 
Mobility is the most evident sign of implant failure and can be presented as rotational, lateral or horizontal, and axial or vertical mobility [15]. There are different terms in the literature associated with biological implant failure or complications like peri-implant diseases, peri-mucositis and peri-implantitis, where the first two are reversible inflammatory reactions around a functioning implant. Peri-implantitis is a chronic inflammation with loss of the supporting tissues around the implant induced by bacterial colonization, facilitated by the implant/abutment gap and by the chemistry and surface roughness of the restorative components $[14,16]$.

Bacteria colonize and develop biofilms on the transmucosal abutment of osseointegrated dental implants. Like the gingival crevice around the natural tooth, the peri-implant mucosa covering the alveolar bone is closely adapted to the implant. In partially edentulous subjects, the developing microbiota around implants closely resembles the microflora of natural teeth [14]. In addition to the dark-pigmented, gram-negative anaerobic rods, other bacteria are associated with peri-implant infections (Bacteroides forsythus, Fusobact. nucleatum, Campylobacter, Peptostreptcc. micros and Prevotella intermedia) [17], and eventually Staphylocc. spp, enterics, and Candida spp [18].

Metals, including $\mathrm{Ti}$, may induce non-specific immunomodulation and self-immunity. In immunologic in vitro tests, sensitization to Ti was observed [19]. Such problems with Ti and the ever-growing expectations on aesthetics lead to increasing interest in all-ceramic implants.

The surface texture of dental implants affects the rate of osseointegration [20] and biomechanical fixation. Surface roughness may be classified as "macro", "micro" and "nano" sized topologies. The "macro" range, from millimetres to $10 \mu \mathrm{m}$, is directly related to implant geometry, with threaded screws and macroporous coatings helping the primary stability of the implants during the early phases of implantation. However, high surface roughness may increase peri-implantitis risk compared with moderate roughness $(1-2 \mu \mathrm{m})$ within the "micron" range $(1-10 \mu \mathrm{m})$, maximizing bone/implant interlocking. Surface profiles in the "nano" range play an important role in protein adsorption and osteoblast adhesion and thus, in osseointegration [21]. No reproducible surface roughness is currently clinically available.

Dental implant failure is an active clinical research area. A number of strategies have been studied to modulate cell/material interactions, which play an important role in determining the short- and long-term implant success rate. This chapter will be mainly focused on the basic aspects to study cell/material interactions in dental implants using progenitor cells and in vitro biofilm formation approaches, as well as basic information related with microengineering technologies to modify dental implant surfaces.

\section{Strategies to study cell/material interactions}

Mesenchymal Stem Cells (MSCs) are commonly isolated from perinatal tissues (i.e, placenta, umbilical cord and blood from the umbilical cord) and postnatal tissues (bone marrow, 
trabecular bone, alveolar bone, cartilage, hair follicles, fat, skin and dental pulp) [22]. Bone marrow and pulp derived cells are frequently used in oral biology research to evaluate the biocompatibility of different dental materials. However, the frequency of MSCs in both tissues is not well known (0.001 to $0.01 \%)$. Bernardo et al. reported that MSCs frequency in bone marrow exhibits an age-related behaviour from 1:10,000 in a new-born to 1:1,000,000 in an 80-year-old subject [23]. Another important aspect is associated with anatomic skeletal site-specific differences [24], where MSCs obtained from calvaria have proven more successful for grafting in craniofacial application than cells obtained from others donor sites.

Different mechanical, chemical, or combined approaches have been used to disrupt the extracellular matrix to isolate MSCs from bone tissue bits or bone marrow. In the mechanical approach, the bone tissue is cut into small pieces using surgical blades, and then either suspended or plated. The main disadvantage of this procedure is shear-stress injury. The enzymatic digestion of the bone chips, with a combination of trypsin and collagenase (chemical-based approach) to obtain a cell suspension, should be avoided because trypsin might damage the cell membrane surface. If these cells are collected for some type of human cell therapy, a complete characterization of these proteases is required by regulatory agencies.

The number of sources for autologous MSCs for dentistry has increased due to the hundreds of mandatory extractions (e.g., third molars and premolars for orthodontic purposes) performed each year, since these tissues are routinely discarded. Many authors have shown that pulp-derived MSCs from deciduous and permanent teeth, as well as from periodontal ligament, might be isolated. These types of MSCs from different niches are heterogeneous and exhibit site-specific features, but in general they are able to produce bone, dentine, cement, and periodontal ligament-like structures [22, 25].

The successful isolation procedure of homogeneous populations is commonly based on morphology at early culture stages, considering that MSCs exhibit a fibroblast-like morphology. In the case of heterogeneous populations, the classification based upon specific markers is more desirable. Although specific and unequivocal markers are not available, an evaluation of non-specific multi-markers allows for a reasonable characterization. Tuan [26] reported that MSCs cells are positive for STRO-1, CD73, CD146, and CD106, and negative for CD11b, CD45, CD34, CD31 and CD117, preferably evaluated by fluorescence-active cell sorting (FACS). Other phenotypic approaches require the evaluation of MSCs capacity for trilineage mesenchymal differentiation (osteoblasts, adipocytes and chondroblasts) under standard in vitro differentiating conditions [23, 27].

Dulbecco's Modified Eagle's (D-MEM) and Minimal Essential Medium ( $\alpha$-MEM) are the most used standard cell culture media for in vitro bone cell studies. They are supplemented with different percentages of fetal bovine serum (FBS, $10 \%$ or 15\%), antibiotics, antimycotics, and ascorbic acid. Coelho, et al. [28] made a comparative study on the behaviour of human bone marrow (hBM) osteoblastic cells cultured in $\alpha$-MEM or D-MEM and they found a similar cell proliferation between both media. However, cells cultured in $\alpha$-MEM exhibited higher ALP levels and earlier formation of mineralized deposits. Serum is essential in 
promoting or inhibiting cell proliferation and differentiation since it is a complex mixture of proteins, growth factors, ions, lipids and hormones.

Fetal Bovine Serum (FBS) is an inexpensive choice to conduct in vitro bone regeneration studies, but Human Serum is another option that can help to obtain more realistic results, and although a direct extrapolation from in vitro studies to clinical situations would be desirable, this has not been possible [29]. Recently, Deorosan and Nauman (2011) evaluated the effects of the concentrations of serum and glucose on the metabolic activity of murine MSCs, and concluded that the effects of the serum percentage (e.g. $2 \%, 5 \%$ and $10 \%$ ) were negligible. However, a high correlation was found between cell viability and glucose concentrations (0.5 to $25 \mathrm{mM})$ [30].

Antibacterial and antimycotic agents are other types of supplements that can be controversial. Both should be avoided because they may affect cell physiology and mask improper aseptic conditions. However, from a realistic point of view, considering the risk of losing irreplaceable MSCs, the standard use of antibacterials (e.g., Penicilin/Streptomycin, $100 \mathrm{IU} / \mathrm{ml}$ and $10 \mathrm{mg} / \mathrm{ml}$, respectively; Gentamicin, $10 \mu \mathrm{g} / \mathrm{ml}$ ) and antimycotics (e.g., Amphotericin B, $0.25 \mu \mathrm{g} / \mathrm{ml}$ ) is required. Also, tetracyclines are often used to take advantage of their Ca-binding and fluorescence properties under UV light, allowing for the quantification of matrix mineralization. Other tetracyclines, like doxycycline and minocycline, when in low concentrations, may stimulate the proliferation of human osteoblastic cells [31].

The main goal of long-term in vitro MSCs cell cultures is their differentiation. To promote osteoblastic differentiation, the most frequently used supplements are ascorbic acid (AA, $50 \mu \mathrm{g} / \mathrm{ml})$, dexamethasone (Dex, $10 \mathrm{nM})$, and $\beta$-glycerolphosphate $(\beta \mathrm{GP}, 10 \mathrm{mM})$ [32]. When tested in vitro, these compounds are able to promote growth and accelerate the differentiation process of osteoprogenitor cells, thus reducing the proliferation period of the developmental sequence in the expression of the osteoblastic phenotype [33]. Coelho and Fernandes studied the proliferation/differentiation of hBMSCs cultured under different conditions of mineralization supplements. Their results show high proliferation in all the tested conditions, but mineralization was only achieved in the presence of $\beta \mathrm{GP}$ and this mineralization was greater in the presence of Dex.[32].

The micro-environment affects the ability of the osteoblast to produce a mineralized matrix, thus compromising the bone repair/regeneration process. Roughness has been considered as a major aspect in the osseointegration of titanium implants. Albrektsson and Wennerberg [34] classified the surface implants as smooth $(0.0-0.4 \mu \mathrm{m})$, minimally rough $(0.5-1.0 \mu \mathrm{m})$, moderately rough $(1.0-2.0 \mu \mathrm{m})$ and rough $(>2.0 \mu \mathrm{m})$. Theoretically, an increased roughness can be associated with a stronger bone response but also a greater potential for periimplantitis and a higher risk of ionic leakage [34]. Other materials based on Co-Cr alloys and AISI 316L stainless steel have been used as dental implants. However, their use is controversial because corrosion products from $\mathrm{Co}-\mathrm{Cr}$ alloys have been demonstrated to affect the cell viability, ALP activity and formation of a mineralized matrix in vitro when using osteoblast-like cells from rat, rabbit and human BM-MSCs [35]. These findings have 
been confirmed with corrosion products from AISI 316L stainless steel (and the isolated Fe, $\mathrm{Ni}$ and $\mathrm{Cr}$ ions). Deleterious dose- and time-dependent effects on ALP activity and matrix mineralization in rat, rabbit BMSCs and human alveolar bone cell cultures have been shown $[33,36]$. On the other hand, the release of ionic species from hydroxyapatite-based materials might be explored to obtain a positive modulation of the osteoblastic cell response. For instance, Si-substituted hydroxyapatite coatings promote osteoblast proliferation and differentiation when compared to hydroxyapatite coatings due, at least in part, to the release of Si ions [37]. The aforementioned studies help to understand the relevance of MSCs and their in vitro osteogenic differentiation as tools to assess bone cell response to materials and agents intended for bone repair/regenerations strategies.

\subsection{Bacterial adhesion process, biofilm formation and in vitro models}

Adherence mechanisms of oral bacteria are essential to bacterial colonization of the oral cavity. In their absence, bacteria become part of the salivary flow and are swallowed. As a result, oral bacteria have developed several mechanisms to fulfill this task. The mechanisms are highly specific; the oral cavity is colonized mainly by bacteria that are exclusively found in it. Through retention, these bacteria can form organized, intimate, multispecies communities referred to as dental plaque and biofilms [38, 39]. Microbial adhesion and the accumulation of pathogenic biofilms are considered to play major roles in the pathogenesis of peri-implantitis and implant loss [40]. Therefore, knowledge about the microbiology around dental implants is essential.

After exposure of an osseointegrated implant to the oral cavity, an acquired pellicle is formed on the implant surface through selective adsorption of the environmental macromolecules including glycoproteins (mucins), proline-rich proteins, enzymes like $\alpha$ amylase, histidine-rich proteins, phosphoproteins like statherin, and other molecules [38, 41]. These are derived mainly from saliva but, in the subgingival region, molecules originate from gingival crevicular fluid [42]. The physicochemical surface properties of a pellicle, including its composition, packing, density, and/or configuration, are largely dependent on the physical and chemical nature of the underlying hard surface.

The adsorption of proteins from an aqueous solution onto a solid surface is the result of various types of interactions that simultaneously occur between all the components, namely the fluid, the solid and the solubilized proteins. The mechanisms involved in pellicle formation include electrostatic, van der Waals, and polarity forces. The polarity of each of these components has great impact on the adsorption process, which is reflected in the hydrophilicity or hydrophobicity of the interacting components [41, 43]. The pellicle plays a decisive role in microbial adhesion, as its constituents may interact with oral microorganisms, either by direct interaction with them, or indirectly by influencing the thermodynamic conditions for microbial adhesion [44].

After formation of the acquired pellicle, bacterial attachment with initial colonizers followed by cell-to-cell adhesion with secondary colonizers occurs on the implant surface [45]. An initial reversible adhesion involves weak, long-range, non-specific physicochemical 
interactions between the charge on the microbial cell surface and that of the acquired pellicle. Microorganisms are usually transported passively to the surface by the flow of saliva or gingival crevicular fluid or by active bacterial movement. A few species (e.g Wolinella, Selenomonas and Campylobacter spp.) found sub-gingivally have flagella and are motile [42]. Alternatively, microorganisms in suspension may also be transported towards each other by microbial (co)aggregates [41].

During the second phase of adhesion, strong, short-range interactions between specific molecules on the bacterial cell surface (adhesins) and complementary molecules (receptors) present in the acquired pellicle can result in irreversible attachment. Oral bacteria generally possess more than one type of adhesin on their cell surface and can participate in multiple interactions both with host molecules and similar receptors on other bacteria (co-adhesion) [46].

Streptococci, the main early colonizers, bind to acidic proline-rich-proteins and other receptors like $\alpha$-amylase and sialic acid in the acquired pellicle [47]. In addition, Actinomyces, which are other primary colonizers, bind to the acquired pellicle and to the streptococci [38, $39,41]$. Consequently, these two groups of primary colonizers are thought to prepare the environment for later colonizers that have more fastidious and slow requirements for growth. Other bacteria, including periodontal pathogens such as Hamophilus actinomycetemcomitans, Porphyromonas gingivalis, Prevotella intermedia, Treponema denticola, Tannerella forsythensis or Fusobacterium species, bind to Streptococci and/or Actinomyces [48]. This stage also involves specific inter-bacterial adhesin-receptor interactions and leads to an increase in the diversity of the biofilm [46].

The increase in attached cell numbers leads to biomass augmentation and the synthesis of exopolymers that form a biofilm matrix. This matrix is a common feature of all biofilms, and is more than a chemical scaffold to maintain the shape of the biofilm. It provides a significant contribution to the structural integrity and general tolerance of biofilms to environmental factors (e.g. desiccation) and antimicrobial agents. The close proximity of cells to one another in a biofilm facilitates numerous synergistic and antagonistic interactions between neighboring species. Within the biofilm, oral bacteria do not exist as independent entities but rather as a coordinated, spatially organized, and fully metabolically integrated microbial community, whose properties are more relevant than the sum of the individual composing species [41, 42, 49].

The physico-chemical characteristics of specific material surfaces are known to significantly influence the bacterial adhesion process. Both surface free energy and surface roughness are known to play major roles in this process [41, 50]. High surface roughness values significantly promote bacterial adhesion by reducing the influence of shear forces on initially attaching bacteria, while materials with high surface free energy values are known to increase bacterial adhesion [51]. Furthermore, the bacterial adhesion process is influenced by the chemical composition, surface hydrophobicity, and the zeta potential of the material [52]. An increased zeta potential, which refers to the electrostatic potential generated by the accumulation of ions on the surface, results in decreased bacterial attachment. Generally, 
hydrophobic microorganisms prefer to attach to hydrophobic substrata, and bacteria with hydrophilic properties prefer hydrophilic materials. Moreover, bacterial adhesion varies between the various bacterial species and strains [50,53].

Understanding how bacteria relate and act within biofilms is essential for the prevention and proper management of dental and periodontal diseases [54]. In order to increase the knowledge concerning biofilm physiology, the creation of models to study and evaluate this complex consorting under controlled conditions is of great interest. Over the past years, several in vivo and in vitro biofilm models have been developed with this intent. However, in vivo studies in both animals and humans are more restricted due to problems with access and sampling and because of complex ethical issues involved $[55,56]$.

The currently available in vitro models clarify extensively the microbial biofilm physiology, micro-ecology, pathology and behaviour. These models are used to replicate environmental conditions in vitro and have served as the major conceptual framework for biofilm research, ranging from static mono-cultures to the development of diverse mixed cultures growing under dynamic conditions. For each particular application, every model has its strengths and weaknesses that can be appropriate for one specific application but not for others [5759]. Two major biofilm models have been studied in the laboratory, namely biofilms grown without a continuous flow of fresh medium, known as static models, and biofilms grown with a continuous flow of fresh medium, known as flow models [60].

The quantification of biofilms started with simpler methods based on the cultivation of the biofilm in the wall of test tubes or well plates, like the microtiter plate method. With this system, biofilms are grown on the bottom of the walls or in a substrate placed on the wells of a microtiter plate, for a desired period of time. Besides its simplicity, this method has several advantages, such as low cost and the small amount of reagents required and allows to perform a large number of tests simultaneously, remaining among the most frequently used models to assess biofilm formation. By running it under static conditions, the environment in the well will change during the experiment, unless the fluid is regularly replaced. Also, during biofilm formation, bacteria may deposit on the substrate and on the bottom of the well, and not actively attach to the surface [55, 61-63].

Recently, a new model where the substrate can be positioned vertically to assure active attachment of the bacteria to the surface was developed. This simple high-throughout active attachment model consists of a lid with 24 clamps were different substrates can be put. This lid is placed in a common 24-well plate allowing the substrates to be vertically positioned during the period of biofilm formation [59, 63, 64].

Since in vivo conditions are almost exclusively dynamic, the use of reactors for the in vitro development of biofilms has been largely applied. These systems normally work using continuous flow to provide nutrients to the growing biofilm and can be used for different purposes [57].

A very frequently used model in the dental research field is the constant depth film fermenter (CDFF), a steady-state model. This system consists of a rotating stainless steel disk 
in which plugs are located. Different materials can be placed and used as substrates for biofilm growth until a maximum thickness has been reached. When reached, the excess biofilm is scraped off and nutrients are distributed into the system. The reactor allows several parameters to be tailored, such as the possibility to choose growth conditionsaerobic or anaerobic- and the option to alter nutrient schemes. This model has been frequently used for dental plaque studies $[56,65,66]$.

Another commonly used system is the CDC biofilm reactor developed in the Centers for Disease Control and Prevention by Donlan, et al. [67, 68]. The reactor has 24 removable surfaces that allow biofilm formation under moderate to high sheer stresses in batch or continuous flow-conditions. It has been used to evaluate biofilm formation and structure and also to test the effects of antimicrobial agents in the biofilm $[67,68]$.
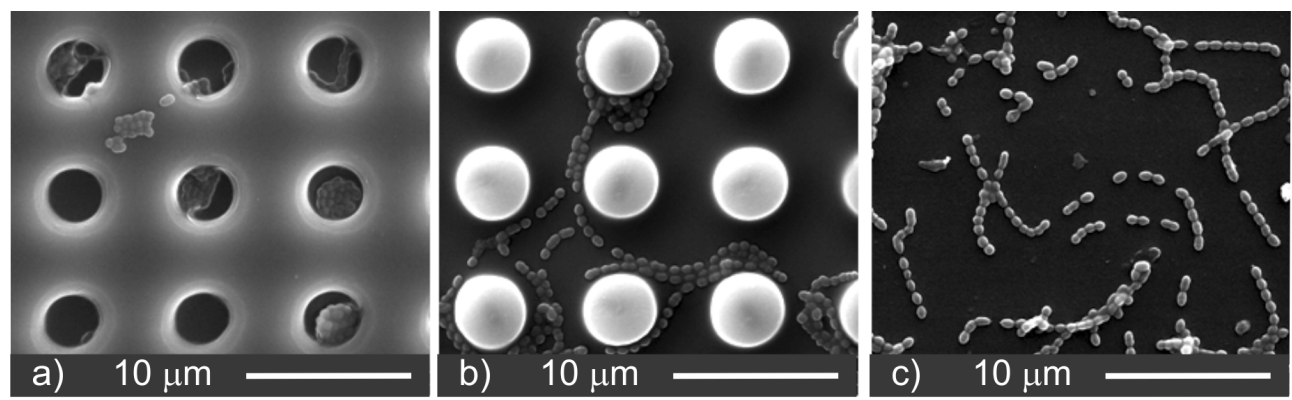

Figure 6. Biofilm formation on a) negative, b) positive relief micropatterned surfaces and c) flat surfaces.

However, the systems described previously lack the possibility of continuously monitoring biofilm growth. Recently, microfluidics systems have been adapted to study biofilm formation. Microfluidics set-ups are normally fabricated through soft-lithography with the size of the channels in the range of 50 to $500 \mu \mathrm{m}$ and flow rates typically very low, between $0.1-50 \mu \mathrm{l} / \mathrm{min}$. These devices have the advantage of simulating biological phenomena with physiological flow velocities, low fluid-to-cell volume ratios, and biomimetic micro-/ nanoengineered surfaces (Figure 6). Also, the small size of the chambers allows for real-time microscopic analysis of biofilm formation $[55,69,70]$.

\section{Micro/nanoscale engineering of cell-material interactions}

Understanding the interactions between cells and biomaterial surfaces at the micron-, submicron-, and nano-scale, is crucial for the production of functional biomedical devices (e.g. implants, biosensors, etc.). Biomaterials are known to elicit specific cellular responses (positive or negative) depending upon the surface chemical and/or physical properties. Surface topography (from the micron- down to the nano-scale), for instance, plays a crucial role in controlling important cellular processes such as adhesion, propagation, proliferation, orientation, migration, differentiation, and reactivity to certain hormones, growth factors and drugs, both in vitro and in vivo [71, 72]. 
The effects of surface microtopography on cell behaviour have been widely documented. Previous research has shown that microtextured surfaces, independent of surface chemistry, exhibit a strong influence on in vitro and in vivo cell behaviour [71, 73, 74].

Surface microroughness affects in vitro adsorption of albumin and fibronectin [75]. Studies performed on randomly oriented microtopographies showed stronger cell adhesion, altered integrin expression, up-regulation of focal contacts, reorganization of the cytoskeleton, changed proliferation, increased differentiation, and enhanced susceptibility to different hormones and growth factors [76-79]. The implementation of lithographic and dry etching techniques from the silicon microelectronics industry into the cell biology field allowed for further studies on the effects of controlled microtopographies on cell behaviour [73]. For the past two decades, in vitro and in vivo studies on controlled microtopographies have shown enhanced cell adhesion and proliferation, cell orientation along the direction of the microfeatures, altered migration and motility patterns, up-regulation of certain cytoskeletal and extracellular matrix proteins, reduced immune response, increased mitochondrial activity, augmented differentiation, etc. Such effects are cell and material-dependent [80-85].

The effects of surface nanotopography on cell functions have been studied since the early 1960 's [86, 87]. Cells are known to be reactive to objects as small as a few nanometers $(\sim 5 \mathrm{~nm})[80]$. A number of different topographical patterns at the submicron and nano-scale (both randomly oriented and controlled) have been explored, including columns, dots, pits, pores, meshwork, gratings, nanophase grain, and random surface roughness [88-95].

Some studies have suggested that osseointegration is a function of the initial interactions that occur between the implant surface and blood. Park and collaborators found that platelet adhesion and activation were increased on micro/nanotextured titanium surfaces compared to polished ones [96], presumably due to the increase in actual surface area (leading to increased protein adsorption), and/or topographically-induced cytoskeletal rearrangement, which could have led to downstream intracellular signaling cascades resulting in platelets aggregation and granules release. This enhanced thrombogenic potential is expected to improve endosseous integration, as osteogenic cells reach the implant surface by migrating through the remnants of the initial osteo-conductive/inductive blood thrombus [97, 98]. Additional studies found that surface micro/nanotextures improve osseointegration due to the fact that the initial fibrin clot is mechanically stabilized by the topography $[99,100]$.

Finally, micro/nanostructured material surfaces have also been shown to provide a greater number of nucleation sites for the precipitation of minerals (e.g. Ca and P) from the blood plasma, which results in the formation of an amorphous apatite layer on the surface of the implant that could potentiate osseointegration [70, 101].

Another way surface micro/nanofeatures could lead to enhanced osseointegration is by directly influencing bone cell responses. Previous studies showed that the initial osteoblastmaterial interactions (i.e. adhesion, spreading and growth) could play an important role in leading to a long-term positive response at the bone-implant interface [70]. Fewster, et al. showed that micron-scale $(1-50 \mu \mathrm{m})$ pillars and pores on polyethylene terephthalate (PET) and polystyrene (PS) surfaces led to improved osteoblast adhesion [102]. Using a cyto- 
detacher, Wang, et al. showed that the adhesion force of osteoblasts to nanostructured titanium surfaces increased $(38.5-58.9 \mathrm{nN})$ in direct proportion to the surface roughness [70]. Webster, et al. found increased vitronectin adsorption and enhanced osteoblast cell adhesion on nanophase alumina surfaces [95]. Wan, et al. showed that osteoblast adhesion was also enhanced on micro- and nanostructured PLLA and PS surfaces, in comparison to their smooth surface counterparts [103]. In this study, no significant differences in the adhesion were found between micro- and nanostructured surfaces, and the cell proliferation levels were similar on textured surfaces compared to the smooth ones. Other groups showed increased osteoblast cell proliferation on nanostructured ceramic surfaces [104, 105]. This indicates that there may be a synergistic effects between surface topography and chemistry that need to be accounted for in some cases, or perhaps that the specific geometrical parameters (e.g. shape, size) of the nanotexture could also determine the degree of cell responses.

Numerous studies have reported an enhanced osteogenic phenotype in response to surface micro- and nanotextures on polymeric, ceramic, and metallic materials [104-109]. Remarkably, Dalby, et al. showed that circular nanostructures can induce osteogenic differentiation in the absence of osteogenic factors in the cell culture medium [110, 111]. More recent reports by Zhao, et al. indicated that the combination of micro- and nanostructures on the same surface may result in a cooperative synergy between the microand nanotopography that ultimately leads to improved bone cell responses [112].

Micro- and nanotextured surfaces also tend to promote increased adhesion in other cell models (e.g. fibroblasts, smooth muscle cells, and chondrocytes), although the stimulus for topography-mediated increased cell adhesion seems to be more prominent for osteoblast cells [99]. Similarly, topography-mediated changes in cell morphology, gene expression, proliferation, and migration, have been reported for human embryonic stem cells, rat aortic endothelial cells, murine macrophages, epithelial, and glial cells, among others [71, 113].

Although surface nanotopography for the most part has been shown to induce "positive" cell responses (e.g. increased adhesion, proliferation, differentiation), there are other reports that suggest that this phenomenon (i.e. topography-mediated cell responses) may be regulated to some degree by the specific geometrical (and perhaps chemical) properties of the patterns. Curtis, et al. studied the effects of different nanofeatures (pillars, pits, randomly distributed Au nanoparticles) on fibroblast and endothelial cell behaviour [114]. The results confirmed increased cell adhesion on the nanogrooves, and decreased adhesion on the nanopillars and nanopits (with adhesion being inversely proportional to the distance between nanofeatures). Cell adhesion on the Au nanoparticles was no different compared to flat surfaces. Dalby, et al. studied fibroblast responses to PMMA nanocolumns and found that cell adhesion and spreading were reduced on the nanocolumns compared to smooth surfaces [115, 116]. The cells growing on the nanocolumns exhibited lower actin polymerization, smaller focal adhesions, and increased filopodia formation. Kunzler, et al. studied osteoblast responses to silica-based nanotopographies, and found that cell adhesion, spreading, and actin polymerization were reduced on the nanostructured surfaces in comparison to smooth ones [117]. 
To summarize, there is rather strong evidence suggesting that micro- and nanoscale surface structures have the potential to modulate cell responses, which could be used to better design biomedical devices (e.g. implants, sensors) by turning on/off specific responses depending on the application. However, the lack of systematic and more controlled studies limits the exploitation of this concept, as it is difficult to reach a consensus on a single microand/or nanotopography that could lead to optimum cell responses for any given application. Nevertheless, recent advances in the fields of micro- and nanofabrication are enabling the development of studies where different topographical parameters (e.g. feature size, organization, density, geometry) could be evaluated in a more controlled manner, which is expected to ultimately lead to a better understanding of the role of surface topography on cellular responses.

A host of different techniques have been developed to imprint features on the surface of a biomaterial at the submicron and nanoscale: laser irradiation, soft lithography, dip-pen nanolithography, capillary lithography, electron beam (e-beam) lithography, microimprinting, interference lithography, nanoimprint, X-ray lithography, polymer demixing, and colloidal lithography among others [88-90, 92, 93, 118-122].

\subsection{Soft Lithography and Sol-Gel Technology}

Lithography has been used since ancient years. Initially, photolithography was introduced in the editorial industry to achieve better printing results. However, this technique contributed later to the development of the integrated circuit industry, and it became the main contributor to the information technology. Photolithography is also essential to produce technology for sensors, microsensors, micromechanical systems (MEMS), microanalytical systems, micro-optical systems and integrated circuits [123, 124].

In 2006, Ferrari, et al. wrote "Less than twenty years ago photolithography and medicine were total strangers to one another .... And then, nucleic acid chips, microfluidics and microarrays entered the scene, and rapidly these strangers became indispensable partners in biomedicine" [125].

In basic terms, photolithography helps to create small structures in a massive scale, but it is not always the best option for all applications since it requires expensive technology. Poor results for curved substrates and the fact that it is limited to photosensitive materials are some of its drawbacks. These limitations inspired two important review papers introducing Soft Lithography (Figure 7) [123, 124].

The soft lithography process can be included among other techniques that are basically rapid prototyping processes. Figure 7 shows a $24 \mathrm{~h}$ flow from the idea to the final prototyping [123]. Establishing borders for soft lithography is a hard task because several techniques, such as microcontact printing $(\mathrm{mCP})$, replica molding, microtransfer molding, micromolding in capillaries (MIMIC) and solvent-assisted micromolding (SAMIM), include the use of stamps or molds as key elements to produce micro- nano-patterns [123]. 


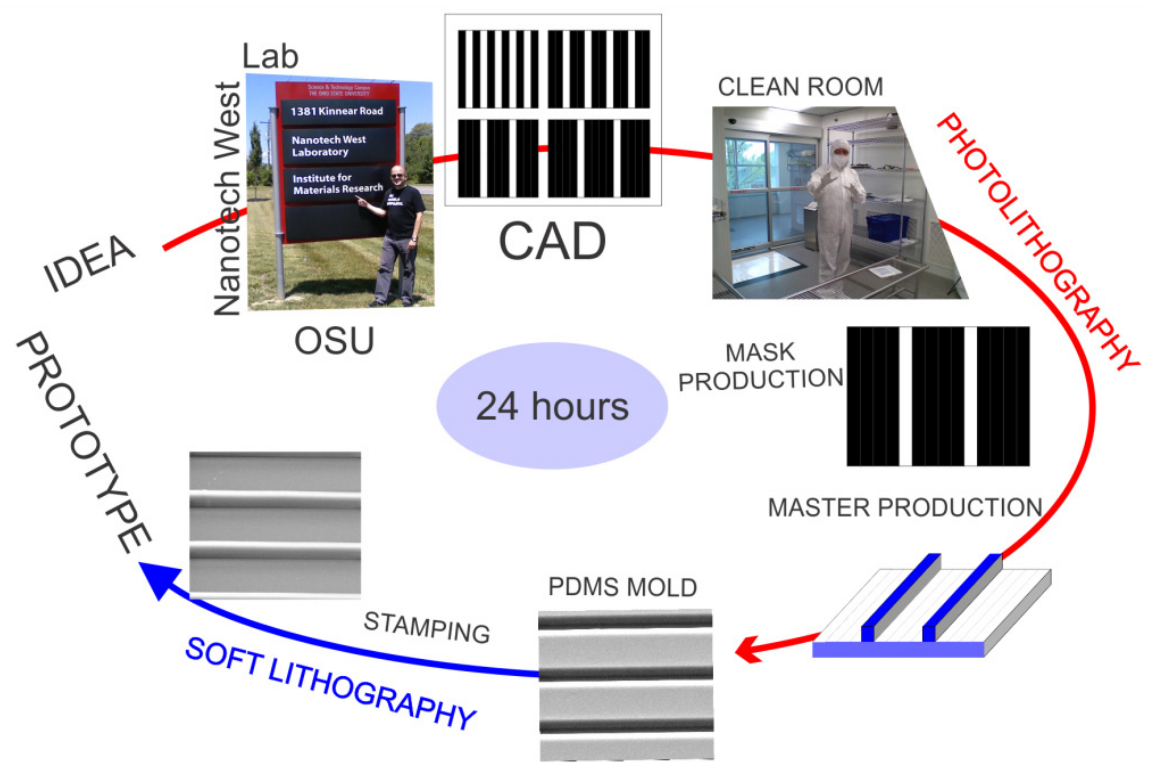

Figure 7. Rapid prototyping using Photolithography and Soft Lithography. Adapted from [123]

Elastomers, such as polydimethylsiloxane (PDMS) have been used in most applications of stamping. Other research groups have also used other elastomers such as polyurethanes, polyimides, and cross-linked Novolac resin (a phenol formaldehyde polymer) [123]. PDMS exhibits advantages such as being chemically inert, good surface reproducibility, limited shrinkage, homogenity, isotropy, transparency, and easily modifiable by plasma. However, its main disadvantages are the swelling in the presence of non-polar solvents, such as toluene and hexane, and forces, like gravity. Adhesion and capillary forces exert stresses on the elastomeric features and cause them to collapse, generating defects in the produced pattern. Therefore, obtaining patterned surfaces with features smaller than $1 \mu \mathrm{m}$ is difficult [123].

Sol-gel is called "the wet chemistry" in processing ceramics, glasses and other materials, but it can be referred to as several chemical reactions occurring during the manufacturing of technological products. Under this term, several techniques of production of materials such as monolithics, powders, fibers, nanospheres, pigments, and coatings have been developed for aerospatial, optical, electronic, refractory, automotive, polymers and sensors, and medical industries [126-130].

First synthesis of silica was described by Ebelmen in 1844, but it found its commercial application in the early 1960's [131]. Since its beginnings in the 1940's, the sol-gel processing has helped to obtain a new generation of materials (ceramic and glasses). Considering the initial precursors, the processing can be divided in aqueous solution of metal salts, metal alkoxide solutions or mixed organic, and inorganic precursors [132]. Frequently, the alkoxides (TEOS/MTES) have been used to produce a hybrid sol. These precursors 
hydrolyze with the formation of partially hydrolyzed products and they subsequently undergo condensation with formation of an oxide network [133, 134]. The sol stage is used to produce thin films by spin coating, dip coating or imprinting.

In general, these materials present high purity and homogeneity, their particle size distribution may be controlled at the nano-scale level, and they require low temperatures to be prepared. In comparison with high temperature processes, these sol/gel materials and processes save energy, minimize evaporation losses and air pollution, and, in general, do not induce reactions with their containers. However, they are not free of disadvantages. Among these disadvantages, the high cost of raw materials, the large shrinkage during processing, the residual hydroxyls, carbon and microporosity, the long times for processing, and the difficulty to adapt them to produce large pieces are found. For additional information, the readers are invited to read more specialized reviews [134, 135].
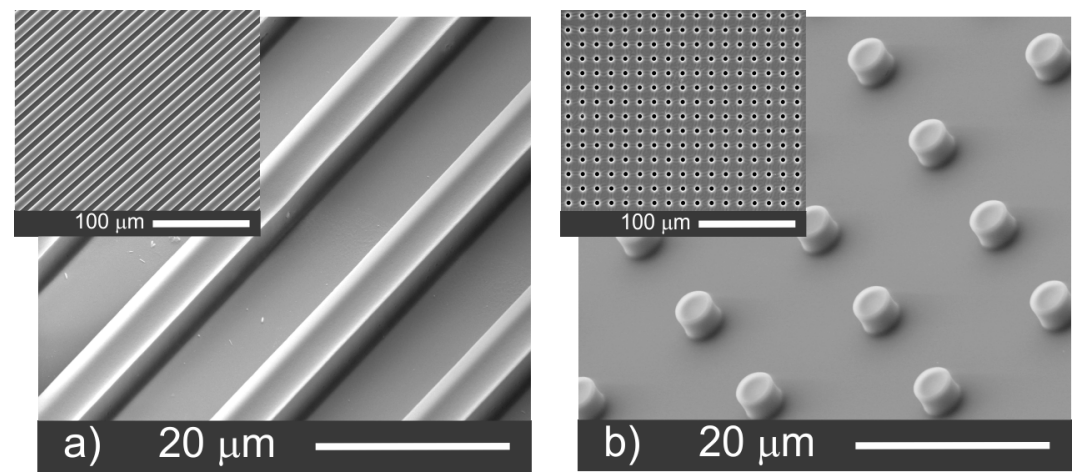

Figure 8. Anisotropic (a) and isotropic (b) silica coatings produced by synergy of soft lithography and sol-gel technology. Inset in both figures shows the PDMS molds.

For optical applications, surface relief features in or on thin films can be used. Specific geometries are used to produce couplers, filters, lenses, beam splitters and mirrors. For biomedical applications, Hench [136] described early that "A common characteristic of glasses, glass-ceramics and ceramics that bond to living tissues is the development of a bioactive hydroxyapatite layer in vivo at body temperature". Also, this author proposed the following categories for materials with the potential for biological or medical use: 1) bioactive sol-gel coatings, 2) bioactive sol-gel glasses, 3) doped sol-gel matrices as biological and chemical sensors and 4) sol-gel matrices with entrapped living organisms.

The synergy between soft lithography and sol-gel has been explored before in the production of membranes and waveguides with a feature size of $1 \mu \mathrm{m}$ [137]. Figure 8 shows anisotropic and isotropic PDMS molds and microstructured silica coatings produced by solgel. Specific shapes and dimensions can be selected depending on the application [138]. 


\subsection{Bioactive Micropatterned Surfaces}

Ceramic nanoparticles can be added to silica thin films in order to increase bioactivity and contact surface area. Hydroxyapatite (HA) is one of the most widely used synthetic calcium phosphates due to its chemical similarities to the inorganic component of hard tissues.
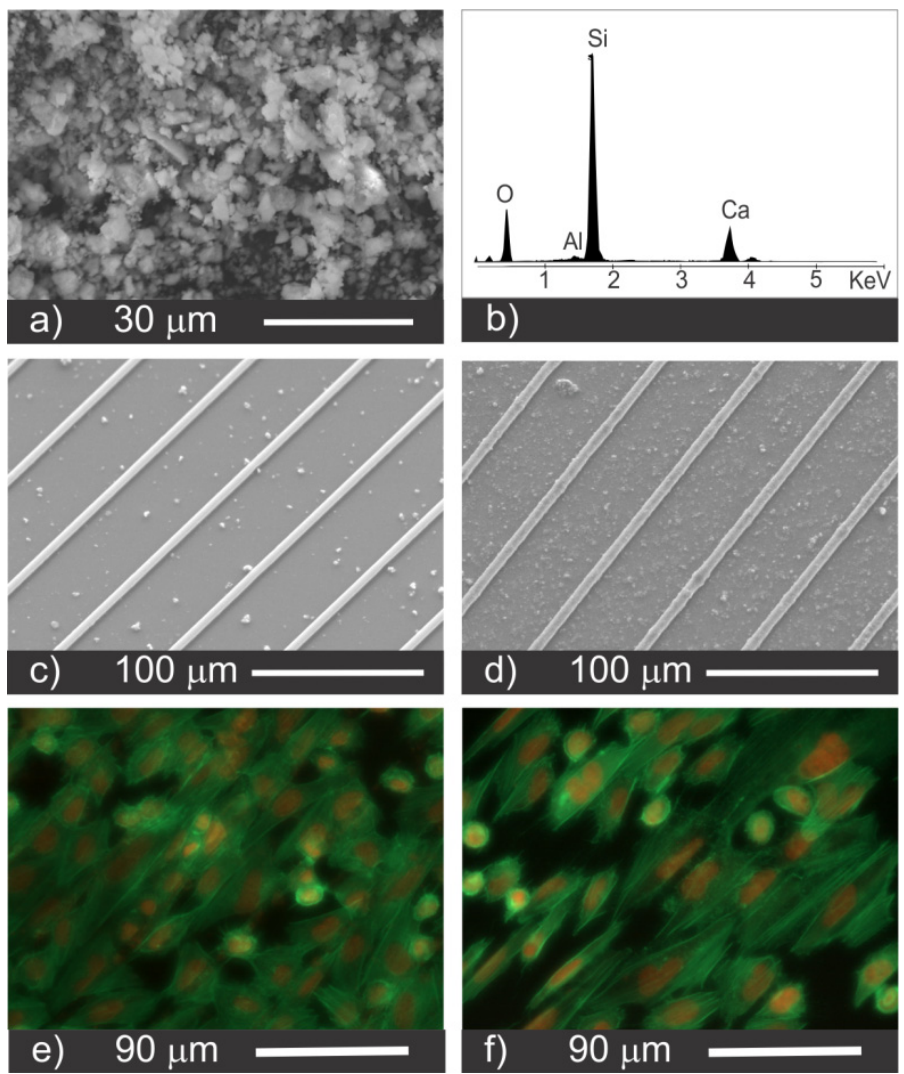

Figure 9. Silica coatings with bioactive Portland cement (PC) particles. SEM images of Portland cement particles (a) Energy Dispersive Spectrum of PC particles (b) micropatterned coating produced by dual (c) and single molding (d) Saos-2 osteoblast cells responses to the produced coatings. Dual (e) and single (f) molding.

HA exhibits exceptional biocompatibility and bioactivity, key features for the formation of a direct and strong interface with bone, and in addition, osteoconductivity, which is the ability to serve as a template for the local formation and growth of new bone [139-141]. Current research is focused on the development of new HA formulations with properties closer to those of living bone, such as nano-sized and monolithic structures [139, 142]. Compared to conventional ceramic formulations, nanophase HA properties such as surface grain size, pore size, wettability, etc., could control protein interactions, thus modulating osteoblast adhesion and long-term functionality [95, 143]. These implant materials are 
suitable for bone replacement and could be useful for additional functions, such as the release of drugs, growth factors, or other substances [144].

Portland cement based materials (e.g. MTA) have been extensively used in the dentistry field for stimulating the formation of cement and dentin (Figure 9a-b) [145]. The high content of $\mathrm{Ca}(\mathrm{OH})_{2}$ of hydrated Portland cement causes it to have an extremely basic $\mathrm{pH}$ ( 12.5-13.0). This basic $\mathrm{pH}$ has been shown to be advantageous for endodontic applications as it prevents bacterial contamination. Moreover, the $\mathrm{Ca}(\mathrm{OH})_{2}$ released under physiological conditions interacts with phosphates in the medium to produce rapid precipitation of amorphous apatite. However, previous research by Gallego-Perez, et al. showed that the showed that the $\mathrm{Ca}(\mathrm{OH})_{2}$ present in hydrated Portland cement could be extremely cytotoxic [146, 147].

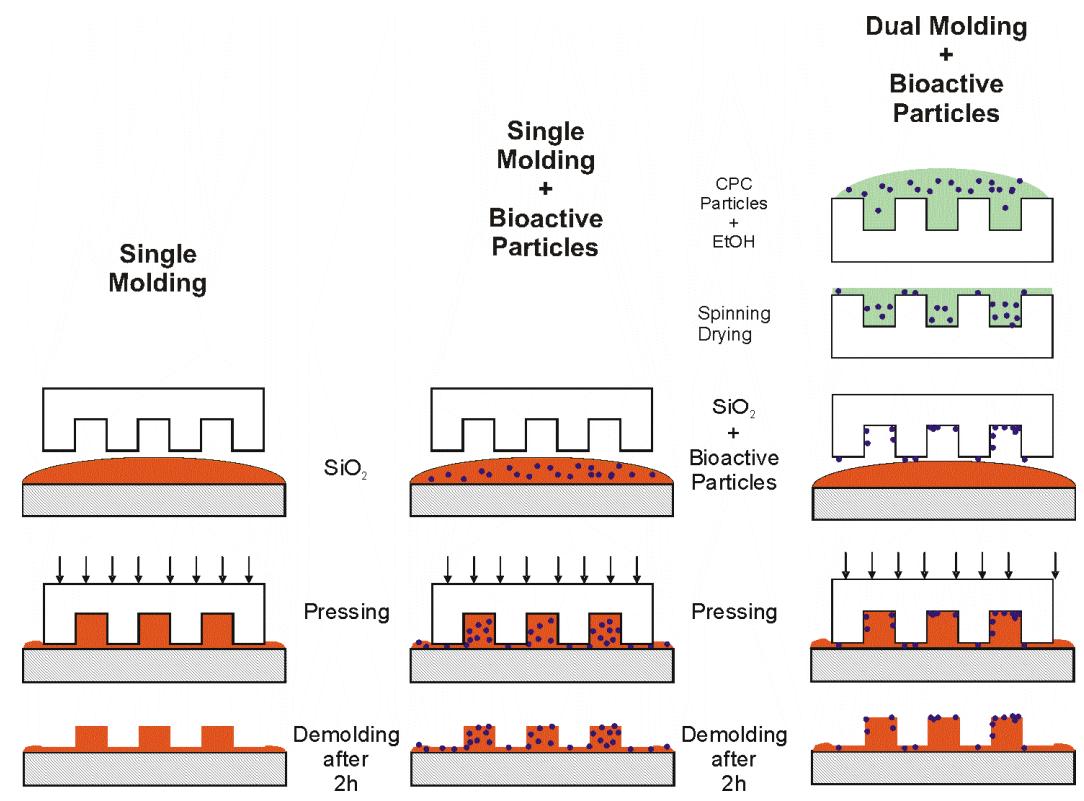

Figure 10. Stamping silica coatings with bioactive particles via single or dual molding technique [148-150].

Such toxic effect effect may not be desirable in certain applications, like implants, as it will prevent adequate cell adhesion and propagation on the surface and cause the formation of a large necrotic zone around the implant after placement, provoking a chronic inflammatory response by the host, which could potentially lead to total rejection of the implant. To avoid this, Gallego-Perez, et al. developed a simple strategy to obtain cytocompatible Portland cement based on the carbonation of the paste. The $\mathrm{CO}_{2}$ introduced during the hydration of Portland cement reacts with the $\mathrm{Ca}(\mathrm{OH})_{2}$ that is being formed to produce calcium carbonate $\left(\mathrm{CaCO}_{3}\right)$, which decreases the $\mathrm{pH}$ of the cement ( 7.4), and provides a more compatible environment for cell growth [146, 147, 151]. More recently, a new method was developed (Figure 10) for the production of cytocompatible Portland cement microparticles, which could be incorporated, along with nano-hydroxyapatite particles, in micropatterned bioactive coatings (Figure 9c-f) of interest to dental implantology [148-150]. 


\section{Future considerations}

Dental implantology is still an area of active research. A growing number of biomaterials, implant surfaces, and geometries, are currently available in the market. However, independent of the selected implant system, a successful therapy always results from the proper interplay between the implant, surrounding soft/hard tissues, and the oral environment.

Different approaches are constantly being developed to modulate the response of MSCs as precursors of differentiated cells. MSCs cells from craniofacial niches are desirable for the repair or replacement of soft and hard oral tissues. Although a host of surface modification strategies can be implemented, micro-/ nanoengineered surfaces have shown great promise for this application, in part due to their ability to properly control cell and tissue adhesion to the implant surface. A close apposition of gingival tissues helps to prevent apical migration of bacteria, which could be responsible for the resorption of the bone crest and implant failure.

Micro-/nanopatterned surfaces are an interesting model to study the basic phenomena associated with osseointegration and biofilm formation on dental materials. In addition, a number of other micro-/nanoscale technologies also facilitate the development of more complex model systems. As an example, microfluidic devices could help to study biofilm formation on micro-/nanoengineered surfaces under dynamic flow, thus resembling more closely the in vivo conditions.

Finally, the synergy between soft lithography and sol-gel chemistry provides several possibilities to develop a new generation of dental implants with micro-/nanopatterned hard surfaces that may lead to improved osseointegration and guided soft/hard tissue regeneration.

\section{Author details}

A. Pelaez-Vargas*

INEB - Instituto de Engenharia Biomédica, Universidade do Porto, Porto, Portugal

Universidade do Porto - Faculdade de Engenharia (FEUP), Departamento de Engenharia

Metalúrgica e Materiais, Porto, Portugal

Universidad Cooperativa de Colombia, Facultad de Odontología, Medellín, Colombia

A. Carvalho, L. Grenho and F.J Monteiro

INEB - Instituto de Engenharia Biomédica, Universidade do Porto, Porto, Portugal

Universidade do Porto - Faculdade de Engenharia (FEUP), Departamento de Engenharia

Metalúrgica e Materiais, Porto, Portugal

D. Gallego-Perez, N. Higuita-Castro and D.J. Hansford

Department of Biomedical Engineering, The Ohio State University and Nanoscale Science and

Engineering Center - NSF, Columbus (OH), USA

J.A. Arismendi

Universidad de Antioquia, Facultad de Odontología, Medellín, Colombia

${ }^{*}$ Corresponding Author 
M.H. Fernandes

Universidade do Porto - Faculdade de Medicina Dentária, Porto, Portugal

M.P. Ferraz

INEB - Instituto de Engenharia Biomédica, Universidade do Porto, Porto, Portugal

CEBIMED - Centro de Estudos em Biomedicina, Universidade Fernando Pessoa, Porto, Portugal

\section{Acknowledgements}

This work was supported partially by the Portuguese Science and Technology Foundation (Scholarship FCT/SFRH/BD/36220/2007 and Grant No. FCT/PTDC/CTM/100120/2008 "Bonamidi"), CRUP - Acções integradas Luso-Espanholas: E46/09, Acciones integradas Hispano-Portuguesas, MICINN: HP2008-0075. NSF Nanoscale Science and Engineering Center fellowship (NSF, Grant No.EEC-0425626), and an U.S. Air Force Office of Scientific Research MURI (Grant No.F49620-03-1-0421).

\section{References}

[1] Petersen P E (2003) The World Oral Health Report 2003: continuous improvement of oral health in the 21st century. The approach of the WHO Global Oral Health Programme. Community Dent Oral Epidemiol. 31: 3-24.

[2] Okeson J P (2003), Causes of functional disturbances in the masticatory system in Management of Temporomandibular Disorders and Occlusion, Okeson J P. London: Mosby 149-189 p.

[3] Sennerby L (2008) Dental implants: matters of course and controversies. Periodontol 2000. 47: 9-14.

[4] Albrektsson T, Sennerby L, and Wennerberg A (2008) State of the art of oral implants. Periodontol 2000. 47: 15-26.

[5] Jaffin R A and Berman C L (1991) The excessive loss of Branemark fixtures in type IV bone: a 5-year analysis. J Periodontol. 62: 2-4.

[6] Moy P K, Medina D, Shetty V, and Aghaloo T L (2005) Dental implant failure rates and associated risk factors. Int J Oral Maxillofac Implants. 20: 569-77.

[7] Al-Zahrani M S (2008) Implant therapy in aggressive periodontitis patients: a systematic review and clinical implications. Quintessence Int. 39: 211-5.

[8] das Neves F D, Fones D, Bernardes S R, do Prado C J, and Neto A J (2006) Short implants--an analysis of longitudinal studies. Int J Oral Maxillofac Implants. 21: 86-93.

[9] Arlin M L (2006) Short dental implants as a treatment option: results from an observational study in a single private practice. Int J Oral Maxillofac Implants. 21: 769-76.

[10] Fugazzotto P A (2008) Shorter implants in clinical practice: rationale and treatment results. Int J Oral Maxillofac Implants. 23: 487-96.

[11] Herrmann I, Lekholm U, Holm S, and Kultje C (2005) Evaluation of patient and implant characteristics as potential prognostic factors for oral implant failures. Int J Oral Maxillofac Implants. 20: 220-30.

[12] Branemark P I, Zarb G, and Albrektsson T Tissue-integrated prostheses. Osseointegration in clinical dentistry. 1985, Chicago: Quintessence Publishing. 
[13] Adell R, Eriksson B, Lekholm U, Branemark P I, and Jemt T (1990) Long-term follow-up study of osseointegrated implants in the treatment of totally edentulous jaws. Int J Oral Maxillofac Implants. 5: 347-59.

[14] Klinge B, Hultin M, and Berglundh T (2005) Peri-implantitis. Dent Clin North Am. 49: 661-76.

[15] Esposito M, Hirsch J-M, Lekholm U, and Thomsen P (1998) Biological factors contributing to failures of osseointegrated oral implants. (I). Success criteria and epidemiology. Eur J Oral Sci. 106: 527-551.

[16] Rimondini L, Cerroni L, Carrassi A, and Torricelli P (2002) Bacterial colonization of zirconia ceramic surfaces: an in vitro and in vivo study. Int J Oral Maxillofac Implants. 17: 793-8.

[17] Tanner A, Maiden M F J, Lee K, Shulman L B, and Weber H P (1997) Dental Implant Infections. Clin Infec Dis. 25: S213-S217.

[18] Leonhardt A, Renvert S, and Dahlen G (1999) Microbial findings at failing implants. Clin Oral Implants Res. 10: 339-45.

[19] Lalor P A, Revell P A, Gray A B, Wright S, Railton G T, and Freeman M A (1991) Sensitivity to titanium. A cause of implant failure? J Bone Joint Surg Br. 73: 25-8.

[20] Boyan B, Lohmann C, Dean D, Sylvia V, Cochran D, and Schwartz Z (2001) Mechanisms involved in osteoblast response to implant surface morphology. Ann Rev Mater Res. 31: 357.

[21] Brett P M, Harle J, Salih V, Mihoc R, Olsen I, Jones F H, and Tonetti M (2004) Roughness response genes in osteoblasts. Bone. 35: 124-33.

[22] Robey P G and Bianco P (2006) The use of adult stem cells in rebuilding the human face. J Am Dent Assoc. 137: 961.

[23] Bernardo M, Locatelli F, and Fibbe W E (2009) Mesenchymal Stromal Cells: A Novel Treatment Modality for Tissue Repair. Ann NY Acad Sci. 1176: 101-117.

[24] Akintoye S O, Lam T, Shi S, Brahim J, Collins M T, and Robey P G (2006) Skeletal sitespecific characterization of orofacial and iliac crest human bone marrow stromal cells in same individuals. Bone. 38: 758-68.

[25] Machado E, Fernandes M H, and Gomes P D (2011) Dental stem cells for craniofacial tissue engineering. Oral Surg Oral Med Oral Pathol Oral Radiol Endod. 113: 728-733.

[26] Tuan R (2011) Role of adult stem/progenitor cells in osseointegration and implant loosening. Int J Oral Maxillofac Implants. 26: 5-62.

[27] Dominici M, Le Blanc K, Mueller I, Slaper-Cortenbach I, Marini F C, Krause D S, Deans R J, Keating A, Prockop D J, and Horwitz E M (2006) Minimal criteria for defining multipotent mesenchymal stromal cells. The International Society for Cellular Therapy position statement. Cytotherapy. 8: 315-317.

[28] Coelho M J, Trigo Cabral A, and Fernandes M H (2000) Human bone cell cultures in biocompatibility testing. Part I: osteoblastic differentiation of serially passaged human bone marrow cells cultured in [alpha]-MEM and in DMEM. Biomaterials. 21: 1087-1094.

[29] Aldahmash A, Haack-Sørensen M, Al-Nbaheen M, Harkness L, Abdallah B, and Kassem M (2011) Human Serum is as Efficient as Fetal Bovine Serum in Supporting Proliferation and Differentiation of Human Multipotent Stromal (Mesenchymal) Stem Cells In Vitro and In Vivo. Stem Cell Rev. 7: 860-8. 
[30] Deorosan B and Nauman E A (2011) The Role of Glucose, Serum, and Three Dimensional Cell Culture on the Metabolism of Bone Marrow-Derived Mesenchymal Stem Cells. Stem Cells Int. 2011: 429187.

[31] Gomes P S and Fernandes M H (2007) Effect of therapeutic levels of doxycycline and minocycline in the proliferation and differentiation of human bone marrow osteoblastic cells. Arch Oral Biol. 52: 251-259.

[32] Coelho M J and Fernandes M H (2000) Human bone cell cultures in biocompatibility testing. Part II: effect of ascorbic acid,[beta]-glycerophosphate and dexamethasone on osteoblastic differentiation. Biomaterials. 21: 1095-1102.

[33] Amaral M, Costa M A, Lopes M A, Silva R F, Santos J D, and Fernandes M H (2002) $\mathrm{Si}(3) \mathrm{N}(4)$-bioglass composites stimulate the proliferation of MG63 osteoblast-like cells and support the osteogenic differentiation of human bone marrow cells. Biomaterials. 23: 4897-906.

[34] Albrektsson T and Wennerberg A (2004) Oral implant surfaces: Part 1 - review focusing on topographic and chemical properties of different surfaces and in vivo responses to them. Int J Prosthodont. 17: 536-43.

[35] Tomas H, Carvalho G S, Fernandes M H, Freire A P, and Abrantes L M (1997) The use of rat, rabbit or human bone marrow derived cells for cytocompatibility evaluation of metallic elements. J Mater Sci Mater Med. 8: 233-8.

[36] Morais S, Sousa J P, Fernandes M H, Carvalho G S, de Bruijn J D, and van Blitterswijk C A (1998) Effects of AISI 316L corrosion products in in vitro bone formation. Biomaterials. 19: 999-1007.

[37] Gomes P S, Botelho C, Lopes M A, Santos J D, and Fernandes M H (2010) Evaluation of human osteoblastic cell response to plasma-sprayed silicon-substituted hydroxyapatite coatings over titanium substrates. J Biomed Mater Res B Appl Biomater. 94: 337-46.

[38] Whittaker C J, Klier C M, and Kolenbrander P E (1996) Mechanisms of adhesion by oral bacteria. Annu Rev Microbiol. 50: 513-52.

[39] Kolenbrander P E, Andersen R N, Blehert D S, Egland P G, Foster J S, and Palmer R J (2002) Communication among oral bacteria. Microbiol Mol Biol Rev. 66: 486-505.

[40] Burgers R, Gerlach T, Hahnel S, Schwarz F, Handel G, and Gosau M (2010) In vivo and in vitro biofilm formation on two different titanium implant surfaces. Clin Oral Implants Res. 21: 156-64.

[41] Teughels W, Van Assche N, Sliepen I, and Quirynen M (2006) Effect of material characteristics and/or surface topography on biofilm development. Clin Oral Implants Res. 17: 68-81.

[42] Marsh P D, Moter A, and Devine D A (2011) Dental plaque biofilms: communities, conflict and control. Periodontol 2000. 55: 16-35.

[43] Hannig C and Hannig M (2009) The oral cavity--a key system to understand substratum-dependent bioadhesion on solid surfaces in man. Clin Oral Investig. 13: 123-39.

[44] Hahnel S, Rosentritt M, Handel G, and Burgers R (2009) Surface characterization of dental ceramics and initial streptococcal adhesion in vitro. Dent Mater. 25: 969-75.

[45] Lee A and Wang H L (2010) Biofilm related to dental implants. Implant Dent. 19: 387-93.

[46] Marsh P D (2004) Dental plaque as a microbial biofilm. Caries Res. 38: 204-11. 
[47] Scannapieco F A (1994) Saliva-bacterium interactions in oral microbial ecology. Crit Rev Oral Biol Med. 5: 203-48.

[48] Heuer W, Elter C, Demling A, Neumann A, Suerbaum S, Hannig M, Heidenblut T, Bach F W, and Stiesch-Scholz M (2007) Analysis of early biofilm formation on oral implants in man. J Oral Rehabil. 34: 377-82.

[49] Branda S S, Vik S, Friedman L, and Kolter R (2005) Biofilms: the matrix revisited. Trends Microbiol. 13: 20-6.

[50] An Y H and Friedman R J (1998) Concise review of mechanisms of bacterial adhesion to biomaterial surfaces. J Biomed Mater Res. 43: 338-48.

[51] Quirynen M and Bollen C M (1995) The influence of surface roughness and surface-free energy on supra- and subgingival plaque formation in man. A review of the literature. J Clin Periodontol. 22: 1-14.

[52] Faltermeier A, Burgers R, and Rosentritt M (2008) Bacterial adhesion of Streptococcus mutans to esthetic bracket materials. Am J Orthod Dentofacial Orthop. 133: S99-103.

[53] Buergers R, Rosentritt M, and Handel G (2007) Bacterial adhesion of Streptococcus mutans to provisional fixed prosthodontic material. J Prosthet Dent. 98: 461-9.

[54] Shaddox L M, Alfant B, Tobler J, and Walker C (2010) Perpetuation of subgingival biofilms in an in vitro model. Mol Oral Microbiol. 25: 81-7.

[55] Coenye T and Nelis H J (2010) In vitro and in vivo model systems to study microbial biofilm formation. J Microbiol Methods. 83: 89-105.

[56] Sissons C H (1997) Artificial dental plaque biofilm model systems. Adv Dent Res. 11: $110-26$

[57] McBain A J (2009) Chapter 4: In vitro biofilm models: an overview. Adv Appl Microbiol. 69: 99-132.

[58] Guggenheim B, Guggenheim M, Gmur R, Giertsen E, and Thurnheer T (2004) Application of the Zurich biofilm model to problems of cariology. Caries Res. 38: 212-22.

[59] Exterkate R A, Crielaard W, and Ten Cate J M (2010) Different response to amine fluoride by Streptococcus mutans and polymicrobial biofilms in a novel highthroughput active attachment model. Caries Res. 44: 372-9.

[60] Benoit M R, Conant C G, Ionescu-Zanetti C, Schwartz M, and Matin A (2010) New device for high-throughput viability screening of flow biofilms. Appl Environ Microbiol. 76: 4136-42.

[61] Stepanovic S, Vukovic D, Hola V, Di Bonaventura G, Djukic S, Cirkovic I, and Ruzicka F (2007) Quantification of biofilm in microtiter plates: overview of testing conditions and practical recommendations for assessment of biofilm production by staphylococci. APMIS. 115: 891-9.

[62] Merritt J H, Kadouri D E, and O'Toole G A (2005) Growing and analyzing static biofilms. Curr Protoc Microbiol. Chapter 1: Unit 1B 1.

[63] Silva T C, Pereira A F, Exterkate R A, Bagnato V S, Buzalaf M A, Machado M A, Ten Cate J M, Crielaard W, and Deng D M (2012) Application of an active attachment model as a high-throughput demineralization biofilm model. J Dent. 40: 41-7.

[64] Deng D M, Hoogenkamp M A, Exterkate R A, Jiang L M, van der Sluis L W, Ten Cate J M, and Crielaard W (2009) Influence of Streptococcus mutans on Enterococcus faecalis biofilm formation. J Endod. 35: 1249-52. 
[65] ten Cate J M (2006) Biofilms, a new approach to the microbiology of dental plaque. Odontology. 94: 1-9.

[66] Wimpenny J W (1997) The validity of models. Adv Dent Res. 11: 150-9.

[67] Donlan R M, Piede J A, Heyes C D, Sanii L, Murga R, Edmonds P, El-Sayed I, and ElSayed M A (2004) Model system for growing and quantifying Streptococcus pneumoniae biofilms in situ and in real time. Appl Environ Microbiol. 70: 4980-8.

[68] Goeres D M, Loetterle L R, Hamilton M A, Murga R, Kirby D W, and Donlan R M (2005) Statistical assessment of a laboratory method for growing biofilms. Microbiology. 151: 757-62.

[69] Yawata Y, Toda K, Setoyama E, Fukuda J, Suzuki H, Uchiyama H, and Nomura N (2010) Bacterial growth monitoring in a microfluidic device by confocal reflection microscopy. J Biosci Bioeng. 110: 130-3.

[70] Wang C C, Hsu Y C, Hsieh M C, Yang S P, Su F C, and Lee T M (2008) Effects of nanosurface properties on initial osteoblast adhesion and $\mathrm{Ca} / \mathrm{P}$ adsorption ability for titanium alloys. Nanotechnology. 19: 335709.

[71] Flemming R G, Murphy C J, Abrams G A, Goodman S L, and Nealey P F (1999) Effects of synthetic micro- and nano-structured surfaces on cell behavior. Biomaterials. 20: 573-88.

[72] Zhao G, Raines A L, Wieland M, Schwartz Z, and Boyan B D (2007) Requirement for both micron- and submicron scale structure for synergistic responses of osteoblasts to substrate surface energy and topography. Biomaterials. 28: 2821-9.

[73] Wilkinson C D W, Riehle M, Wood M, Gallagher J, and Curtis A S G (2002) The use of materials patterned on a nano-and micro-metric scale in cellular engineering. Mater Sci Eng C. 19: 263-269.

[74] Yim E K F and Leong K W (2005) Significance of synthetic nanostructures in dictating cellular response. Nanomedicine. 1: 10-21.

[75] Francois P, Vaudaux P, Taborelli M, Tonetti M, Lew D P, and Descouts P (1997) Influence of surface treatments developed for oral implants on the physical and biological properties of titanium. (II) Adsorption isotherms and biological activity of immobilized fibronectin. Clin Oral Implants Res. 8: 217-25.

[76] Keller J C, Schneider G B, Stanford C M, and Kellogg B (2003) Effects of implant microtopography on osteoblast cell attachment. Implant Dent. 12: 175-81.

[77] Martin J Y, Schwartz Z, Hummert T W, Schraub D M, Simpson J, Lankford J, Jr., Dean D D, Cochran D L, and Boyan B D (1995) Effect of titanium surface roughness on proliferation, differentiation, and protein synthesis of human osteoblast-like cells (MG63). J Biomed Mater Res. 29: 389-401.

[78] Raz P, Lohmann C H, Turner J, Wang L, Poythress N, Blanchard C, Boyan B D, and Schwartz Z (2004) 1alpha,25(OH)2D3 regulation of integrin expression is substrate dependent. J Biomed Mater Res A. 71: 217-25.

[79] Brunette D M (1988) The effects of implant surface topography on the behavior of cells. Int J Oral Maxillofac Implants. 3: 231-46.

[80] Curtis A and Wilkinson C (1997) Topographical control of cells. Biomaterials. 18: 157383.

[81] Curtis A S G and Clark P (1990) The effects of topographic and mechanical properties of materials on cell behavior. Crit. Rev. Biocompat. 5: 343-363. 
[82] Clark P (1994) Cell behaviour on micropatterned surfaces. Biosens Bioelectron. 9: 657661.

[83] von Recum A F and van Kooten T G (1995) The influence of micro-topography on cellular response and the implications for silicone implants. J Biomater Sci Polym Ed. 7: 181-98.

[84] Weiss P (1958) Cell contact. Int Rev Cyt. 7: 391-423.

[85] Singhvi R, Stephanopoulos G, and Wang D I (1994) Effects of substratum morphology on cell physiology. Biotechnol Bioeng. 43: 764-71.

[86] Rosenberg M D (1963) Cell guidance by alterations in monomolecular films. Science. 139: 411.

[87] Rosenberg M D (1962) Long-range interactions between cell and substratum. Proc Natl Acad Sci USA. 48: 1342.

[88] Curtis A S G, Gadegaard N, Dalby M J, Riehle M O, Wilkinson C D W, and Aitchison G (2004) Cells react to nanoscale order and symmetry in their surroundings. IEEE Trans Nanobioscience. 3: 61-65.

[89] Kim D H, Kim P, Song I, Cha J M, Lee S H, Kim B, and Suh K Y (2006) Guided threedimensional growth of functional cardiomyocytes on polyethylene glycol nanostructures. Langmuir. 22: 5419-26.

[90] Wood M A, Wilkinson C D, and Curtis A S (2006) The effects of colloidal nanotopography on initial fibroblast adhesion and morphology. IEEE Trans Nanobioscience. 5: 20-31.

[91] Sapelkin A V, Bayliss S C, Unal B, and Charalambou A (2006) Interaction of B50 rat hippocampal cells with stain-etched porous silicon. Biomaterials. 27: 842-6.

[92] Zhu B, Lu Q, Yin J, Hu J, and Wang Z (2005) Alignment of osteoblast-like cells and cellproduced collagen matrix induced by nanogrooves. Tissue Eng. 11: 825-34.

[93] Zanello L P, Zhao B, Hu H, and Haddon R C (2006) Bone cell proliferation on carbon nanotubes. Nano Lett. 6: 562-7.

[94] Miller D C, Thapa A, Haberstroh K M, and Webster T J (2004) Endothelial and vascular smooth muscle cell function on poly(lactic-co-glycolic acid) with nano-structured surface features. Biomaterials. 25: 53-61.

[95] Webster T J, Schadler L S, Siegel R W, and Bizios R (2001) Mechanisms of enhanced osteoblast adhesion on nanophase alumina involve vitronectin. Tissue Eng. 7: 291-301.

[96] Park J Y, Gemmell C H, and Davies J E (2001) Platelet interactions with titanium: modulation of platelet activity by surface topography. Biomaterials. 22: 2671-2682.

[97] Body S C (1996) Platelet activation and interactions with the microvasculature. J Cardiovasc Pharmacol. 27: 13.

[98] Hong J, Andersson J, Ekdahl K N, Elgue G, AxÃ@n N, Larsson R, and Nilsson B (1999) Titanium is a highly thrombogenic biomaterial: possible implications for osteogenesis. Thromb Haemost. 82: 58-64.

[99] Mendonca G, Mendonca D, Aragao F J L, and Cooper L F (2008) Advancing dental implant surface technology - from micron- to nanotopography. Biomaterials. 29: 38223835.

[100] Grew J C, Ricci J L, and Alexander H (2008) Connective-tissue responses to defined biomaterial surfaces. II. Behavior of rat and mouse fibroblasts cultured on microgrooved substrates. J Biomed Mater Res A. 85: 326-335. 
[101] Kokubo T and Takadama H (2006) How useful is SBF in predicting in vivo bone bioactivity? Biomaterials. 27: 2907-2915.

[102] Fewster S D, Coombs R R H, Kitson J, and Zhou S (1994) Precise ultrafine surface texturing of implant materials to improve cellular adhesion and biocompatibility. Nanobiology. 3: 201-210.

[103] Wan Y, Wang Y, Liu Z, Qu X, Han B, Bei J, and Wang S (2005) Adhesion and proliferation of OCT-1 osteoblast-like cells on micro-and nano-scale topography structured poly (L-lactide). Biomaterials. 26: 4453-4459.

[104] Popat K C, Leoni L, Grimes C A, and Desai T A (2007) Influence of engineered titania nanotubular surfaces on bone cells. Biomaterials. 28: 3188-97.

[105] Popat K C, Chatvanichkul K I, Barnes G L, Latempa T J, Jr., Grimes C A, and Desai T A (2007) Osteogenic differentiation of marrow stromal cells cultured on nanoporous alumina surfaces. J Biomed Mater Res A. 80: 955-64.

[106] Matsuzaka K, Walboomers F, de Ruijter A, and Jansen J A (2000) Effect of microgrooved poly-l-lactic (PLA) surfaces on proliferation, cytoskeletal organization, and mineralized matrix formation of rat bone marrow cells. Clin Oral Implants Res. 11: 325-33.

[107] Matsuzaka K, Walboomers X F, de Ruijter J E, and Jansen J A (1999) The effect of polyL-lactic acid with parallel surface micro groove on osteoblast-like cells in vitro. Biomaterials. 20: 1293-301.

[108] Groessner-Schreiber B and Tuan R S (1992) Enhanced extracellular matrix production and mineralization by osteoblasts cultured on titanium surfaces in vitro. J Cell Sci. 101: 209-217.

[109] Abron A, Hopfensperger M, Thompson J, and Cooper L F (2001) Evaluation of a predictive model for implant surface topography effects on early osseointegration in the rat tibia model. J Prosthet Dent. 85: 40-6.

[110] Dalby M J, McCloy D, Robertson M, Agheli H, Sutherland D, Affrossman S, and Oreffo R O (2006) Osteoprogenitor response to semi-ordered and random nanotopographies. Biomaterials. 27: 2980-7.

[111] Dalby M J, Gadegaard N, Tare R, Andar A, Riehle M O, Herzyk P, Wilkinson C D, and Oreffo R O (2007) The control of human mesenchymal cell differentiation using nanoscale symmetry and disorder. Nat Mater. 6: 997-1003.

[112] Zhao L, Mei S, Chu P K, Zhang Y, and Wu Z (2010) The influence of hierarchical hybrid micro/nano-textured titanium surface with titania nanotubes on osteoblast functions. Biomaterials. 31: 5072-5082.

[113] Engel E, Martinez E, Mills C A, Funes M, Planell J A, and Samitier J (2009) Mesenchymal stem cell differentiation on microstructured poly (methyl methacrylate) substrates. Ann Anat. 191: 136-44.

[114] Curtis A and Wilkinson C (2001) Nanotechniques and approaches in biotechnology. Trends Biotechnol. 19: 97-101.

[115] Dalby M J, Riehle M O, Sutherland D S, Agheli H, and Curtis A S G (2004) Changes in fibroblast morphology in response to nano-columns produced by colloidal lithography. Biomaterials. 25: 5415-5422. 
[116] Dalby M J, Berry C C, Riehle M O, Sutherland D S, Agheli H, and Curtis A S G (2004) Attempted endocytosis of nano-environment produced by colloidal lithography by human fibroblasts. Exp Cell Res. 295: 387-394.

[117] Kunzler T P, Huwiler C, Drobek T, Voros J, and Spencer N D (2007) Systematic study of osteoblast response to nanotopography by means of nanoparticle-density gradients. Biomaterials. 28: 5000-5006.

[118] Teixeira A I, Nealey P F, and Murphy C J (2004) Responses of human keratocytes to micro- and nanostructured substrates. J Biomed Mater Res A. 71: 369-76.

[119] Lee K B, Park S J, Mirkin C A, Smith J C, and Mrksich M (2002) Protein nanoarrays generated by dip-pen nanolithography. Science. 295: 1702-5.

[120] Karuri N W, Liliensiek S, Teixeira A I, Abrams G, Campbell S, Nealey P F, and Murphy C J (2004) Biological length scale topography enhances cell-substratum adhesion of human corneal epithelial cells. J Cell Sci. 117: 3153-64.

[121] Baac H, Lee J H, Seo J M, Park T H, Chung H, Lee S D, and Kim S J (2004) Submicronscale topographical control of cell growth using holographic surface relief grating. Mater Sci Eng C. 24: 209-212.

[122] Berry C C, Dalby M J, McCloy D, and Affrossman S (2005) The fibroblast response to tubes exhibiting internal nanotopography. Biomaterials. 26: 4985-92.

[123] Xia Y and Whitesides G M (1998) Soft Lithography. Angew Chem Int Edit. 37: 550-575.

[124] Xia Y and Whitesides G M (1998) Soft lithography. Ann Rev Mater Sci. 28: 153-184.

[125] Ferrari M, Desai T, and Bhatia S (2006), Therapeutic and Micro/Nanotechnology in BioMEMS and Biomedical Technology, Ferrari M. New York: Springer xxi p.

[126] Arkles B (2001) Commercial application of Sol-Gel derived Hybrid materials. MRS bulletin. 5: 402-407.

[127] Chou T, P. and Cao G (2003) Adhesion of Sol-Gel-Derived Organic-Inorganic Hybrid Coatings on Polyester. J Sol-Gel Sci Techn. V27: 31-41.

[128] Nazeri A, Trzaskoma-Paulette P P, and Bauer D (1997) Synthesis and Properties of Cerium and Titanium Oxide Thin Coatings for Corrosion Protection of 304 Stainless Steel. J Sol-Gel Sci Techn. V10: 317-331.

[129] Zhang Q, Whatmore R, and Vickers M E (1999) A Comparison of the Nanostructure of Lead Zirconate, Lead Titanate and Lead Zirconate Titanate Sols. J Sol-Gel Sci Techn. V15: 13-22.

[130] Zhong J and Greenspan D C (2000) Processing and properties of sol-gel bioactive glasses. J Biomed Mater Res. 53: 694-701.

[131] Livage J (1997) Sol-gel processes. Current Opin Solid St Mater Sc. 2: 132-138.

[132] Dimitriev Y, Ivanova Y, and Iordanova R (2008) History of Sol-Gel Science and Technology (Review). J Univ Chem Technol Metal. 43: 181-192.

[133] Guglielmi M (2010), Glass: Sol-gel coatings in Encyclopedia of Materials: Science and Technology, Buschow K H J, Cahn R, Flemings M, Ilschner B, Kramer E, Mahajan S, and Veyssiere P. Amsterdam: Elsevier 3575-3579 p.

[134] Brinker C, Ashley C, Cairncross R, Chen K, Hurd A, Reed S, Samuel J, Schunk PR, RW S, and Scotto C (1996), Sol-gel derived ceramic film - fundamentals and applications in Metallurgical and ceramic protective coatings, Stern K H. London: Chapman \& Hall 112-151 p. 
[135] Strawbridge I (1992), Glass formation by the sol-gel process in High-performance glasses, Cable M a P, JM. NJ: Chapman and Hall 51-85 p.

[136] Hench L L (1997) Sol-gel materials for bioceramic applications. Curr Opin Solid State Mater Sci. 2: 604-610.

[137] Marzolin C, Smith S P, Prentiss M, and Whitesides G M (1998) Fabrication of Glass Microstructures by Micro-Molding of Sol-Gel Precursors. Adv Mater. 10: 571-574.

[138] Pelaez-Vargas A, Gallego-Perez D, Ferrell N, Fernandes M H, Hansford D, and Monteiro F J (2010) Early spreading and propagation of human bone marrow stem cells on isotropic and anisotropic topographies of silica thin films produced via microstamping. Microsc Microanal. 16: 670-6.

[139] Ferraz M P, Monteiro F J, and Manuel C M (2004) Hydroxyapatite nanoparticles: A review of preparation methodologies. J Appl Biomater Biomech. 2: 74-80.

[140] Best S M, Porter A E, Thian E S, and Huang J (2008) Bioceramics: Past, present and for the future. J Eur Ceram Soc. 28: 1319-1327.

[141] Vallet-Regi M (2001) Ceramics for medical applications. Journal of the Chemical Society-Dalton Transactions. 97-108.

[142] Chevalier J and Gremillard L (2009) Ceramics for medical applications: A picture for the next 20 years. J Eur Ceram Soc. 29: 1245-1255.

[143] Manuel C M, Ferraz M P, and Monteiro F J (2003) Synthesis of hydroxyapatite and tricalcium phosphate nanoparticles preliminary studies. Bioceramics 15. 240-2: 555-558.

[144] Muller-Mai C M, Stupp S I, Voigt C, and Gross U (1995) Nanoapatite and organoapatite implants in bone: histology and ultrastructure of the interface. J Biomed Mater Res. 29: 9-18.

[145] Sarkar N K, Caicedo R, Ritwik P, Moiseyeva R, and Kawashima I (2005) Physicochemical basis of the biologic properties of mineral trioxide aggregate. J Endod. 31: 97-100.

[146] Gallego-Perez D, Higuita-Castro N, Quiroz F G, Posada O M, Lopez L E, Litsky A S, and Hansford D J (2011) Portland cement for bone tissue engineering: Effects of processing and metakaolin blends. J Biomed Mater Res B Appl Biomater. 98B: 308-15.

[147] Higuita-Castro N, Gallego-Perez D, Pelaez-Vargas A, Garcia Quiroz F, Posada O M, Lopez L E, Sarassa C A, Agudelo-Florez P, Monteiro F J, Litsky A S, and Hansford D J (2012) Reinforced Portland cement porous scaffolds for load-bearing bone tissue engineering applications. J Biomed Mater Res B Appl Biomater. 100B: 501-507.

[148] Pelaez-Vargas A, Gallego-Perez D, Higuita-Castro N, Ferrell N, Hansford D, and Monteiro F Silica coatings with Portland cement particles for dental implant surfaces based on sol-gel micromolding. in Biomedical Engineering Society 2009. Pittsburg, PA: BMES CD PS 10A-23

[149] Pelaez-Vargas A, Higuita-Castro N, Gallego-Perez D, Hansford D, and Monteiro F (2010) Portland particulated silica coatings - Comparison between two coating techniques. J Dental Research. 89: 4006.

[150] Carvalho A, Pelaez-Vargas A, Gallego-Perez D, Fernandes M, Hansford D, and Monteiro F (2011) Adhesion and proliferation of mesenchymal stem cells on micropatterned thin films modified with nanohydroxyapatite particles. Bone. 48: S106.

[151] Gallego D, Ferrell N, Sun Y, and Hansford D J (2008) Multilayer micromolding of degradable polymer tissue engineering scaffolds. Mater Sci Eng C. 28: 353-358. 